\title{
On-chip environmentally assisted cracking in thin freestanding $\mathrm{SiO}_{2}$ films
}

\author{
Sahar Jaddi, ${ }^{1,2}$, Jean-Pierre Raskin², Thomas Pardoen ${ }^{1, a)}$ \\ ${ }^{1}$ Institute of Mechanics, Materials and Civil Engineering (iMMC), UCLouvain, 1348 Louvain, Belgium \\ ${ }^{2}$ Institute of Information and Communication Technologies, Electronics and Applied Mathematics (ICTEAM), UCLouvain, 1348 Louvain, Belgium \\ a) Address all correspondence to this author. e-mail: Thomas.Pardoen@uclouvain.be \\ Received: 14 December 2020; accepted: 26 March 2021; published online: 14 April 2021
}

An on-chip fracture mechanics method is extended to characterize subcritical crack growth in submicron freestanding films. The method relies on a self-actuated concept based on MEMS fabrication principles. The configuration consists of a notched specimen attached to actuator beams involving high internal stress. Upon release, a crack initiates at the notch, propagates, and arrests. Several improvements are worked out to limit the mode III component and to avoid crack kinking. The method is applied to subcritical crack growth in 140 -nm-thick $\mathrm{SiO}_{2}$ films under different humidity conditions. The data reduction scheme relates crack growth rate to stress intensity factor. The static fracture toughness value is $\sim 0.73 \mathrm{MPa} \sqrt{\mathrm{m}}$, with standard error of $0.01 \mathrm{MPa} \sqrt{\mathrm{m}}$ and standard deviation of $0.17 \mathrm{MPa} \sqrt{\mathrm{m}}$. Subcritical crack growth rates are much smaller than in bulk specimens. A major advantage is that many test samples can be simultaneously monitored while avoiding any external equipment.

\section{Introduction}

Subcritical crack growth in thin films is a concern for the durability of micro- and nanodevices. Most flexible electronic devices like solar cells, stretchable devices, or flexible microfluidics are subjected to environmental conditions as well as to constant or cyclic external forces. For instance, microfluidics onchip devices are supposed to be in contact with fluids such for instance blood, mucus, and sweat for applications in the medical field. Besides, MEMS devices or other types of microsensors are packaged in or exposed during operation to ambient air. In all these systems, the crack driving force comes from the superposition of the internal stress and external loading, both possibly changing with time. The cracking resistance also evolves with time as a result of materials aging due to environmental effects. Depending on the magnitude of the stress intensity factor, $K$, the cracking resistance can be dominated by diffusion kinetics, by chemical reaction kinetics at the crack tip, or by the timeindependent failure mechanisms when $K$ is close to the static fracture toughness $K_{\mathrm{Ic}}[1-4]$.

The subcritical crack growth resistance is most often characterized using a film-on-deformable-substrate configuration. The film is deposited on a polymer or on a metal with a sufficiently high capacity for homogenous deformation up to large strains. The system is stretched/loaded in a chamber under the environmental conditions of interest, and the cracking process is directly monitored over time using optical, electron, or atomic force microscopy or indirectly using electrical measurements. There are different possible variants involving fixed load or displacement, constant displacement (or load) rate, or cyclic loading. As a representative and well-documented recent study using such a method, Kim et al. investigated the time-dependent crack growth behavior of amorphous silicon nitride ( $\mathrm{SiN})$ deposited on top of polyethylene terephthalate (PET) substrate by plasmaenhanced chemical vapor deposition, $\operatorname{PECVD}[5,6]$. A microtensile testing stage was coupled to optical microscopy to measure the crack extension and time-dependent crack propagation. The tests, conducted in a dry environment or laboratory air, revealed accelerated crack growth in the presence of moisture. A numerical model was established to withdraw the contribution of the polymer relaxation on the driving force for the crack extension. In a recent extension of this work, the time of the experiment was increased to 5 days in order to analyze the effect of substrate damage on possible crack penetration within the substrate and the interaction with neighboring cracks [7]. A substrate with higher tensile strength leads to a smaller number of cracks and a more stable crack growth process. The advantages 
of a film-on-substrate method are the relative simplicity, the capacity to simultaneously monitor many cracks, hence to provide statistical data and to perform in situ observations of crack growth.

Nevertheless, the film-on-deformable-substrate configuration has also some shortcomings. First, the film is not necessarily deposited on the same material as the one used in the application of interest, which may affect its microstructure and internal stress. Secondly, the crack driving force expressed through $K$ or through the energy release rate $G$ depends on the mechanical behavior of the substrate. In the case of an elastic film on an elastic substrate, the elastic mismatch effect, rationalized through Dundur's coefficients, on $K$ or $G$ is well documented and modeled $[8,9]$. In the case of viscoelasticity or substrate cracking such as explained for the example of the previous paragraph, the impact on the crack driving force within the film is significant and difficult to deconvolute even with sophisticated finite element (FE) simulations. Thirdly, crack tip dissipation within the substrate due to viscoelastic or viscoplastic effects as well as due to damage will add an extrinsic contribution to the cracking resistance $G_{\mathrm{c}}$ and make it larger than the cracking resistance of the film alone. This extrinsic contribution might not be representative of the real crack tip dissipation in the film in the specific stack and substrate of the application. It has even been demonstrated that subcritical crack growth can occur in a film that should normally be immune to it when deposited on top of a viscous layer [8]. A final drawback of this method is the time limitation associated with the use of an external equipment to impose the loading.

As a remedy to some of the shortcomings indicated above, a method to address subcritical crack growth measurements in freestanding films, with thickness in the submicron range, is of definitive interest to the materials community. A few earlier studies can be found in the literature dealing with freestanding films. For instance, Fitzgerald et al. [10] studied subcritical crack growth in 150-nm-thick notched single-crystal silicon specimens using a compression double cantilever beam technique with crack extension measured based on the variation of the electrical resistance of a Ti thin film deposited on the side face of the test sample. Both constant displacement rate and constant loading were applied to initiate and propagate the crack. This technique relies on the use of an external apparatus that limits the duration of the experiment to $24 \mathrm{~h}$. The test specimen included a notch and not a real sharp pre-crack. Besides, the top Ti film could artificially modify the chemical conditions on the test specimen. Hatty et al. [11] investigated subcritical crack growth in freestanding $\mathrm{SiO}_{2}$ films relying upon using the internal stress present in the film as an actuation principle. The cracking initiates from a pre-crack produced by indenting the substrate nearby before the release of the film from the substrate. This method gave very valuable data, with, as main limitations, the instability of the cracking process soon after initiation and the relative complexity of the pre-cracking method.

Our method directly elaborates and enhances the test design and protocol described in Jaddi et al. [12], which itself extends the working principle proposed by Hatty et al. [11] further elaborated at UCLouvain during the last decade mainly for tensile testing [13-18]. The principle of the method is shown in Fig. 1. A sacrificial layer is deposited on top of a Si substrate followed by another layer with large tensile internal stress. Two beams are produced by lithography, named "actuator beams". The specimen layer is then deposited and patterned afterward, partly overlapping with the actuator. A notch is present in the middle of the specimen. Once the sacrificial layer is etched away, the actuators contract and pull on the specimen. If the applied displacement is large enough, a crack initiates at the notch root and propagates. The design has been selected such as to involve a decrease of the crack driving force after some amount of crack growth leading to crack arrest [12]. This solves the two limitations of the early approach by Hatty et al. [11]: the stability issue and the complexity associated to the pre-cracking step. The fracture toughness is extracted from the final crack arrest length. The approach requires accurate estimates of the stress intensity factor (SIF) $K_{\mathrm{I}}$ based on analytical equations or FE simulations [12]. The measured fracture toughness is thus the crack arrest fracture toughness, which should be similar to the initiation fracture toughness for brittle materials showing limited crack tip dissipation.

The first objective of this paper is to present new extensions of the original static fracture method described above [12]. The first generation of on-chip test structures suffered from problems of spurious out-of-plane displacements leading to an uncontrolled mode III component, frequent occurrences of the crack kinking out of the straight path, and leading to specimen breaking as well as from some fracture events at the overlap between the specimen and actuator layer. Finally, the overetching of the anchoring section was not properly modeled. The goal was thus to provide remedies to these issues and to increase the accuracy and yield of the method. These extensions, which were found essential to allow a further application to subcritical crack growth investigations, will be validated for different types of specimens studied in our group recently.

As a second objective, the enhanced test method is applied to subcritical crack growth. This involves a specific data reduction scheme to extract crack velocity versus $K$ data. The method is validated by testing $\mathrm{SiO}_{2}$ thin films, as motivated by its importance in applications and by the availability of robust reference data. Indeed, $\mathrm{SiO}_{2}$ films are extensively used for instance in electronic applications as protective layers, as dielectric materials, 

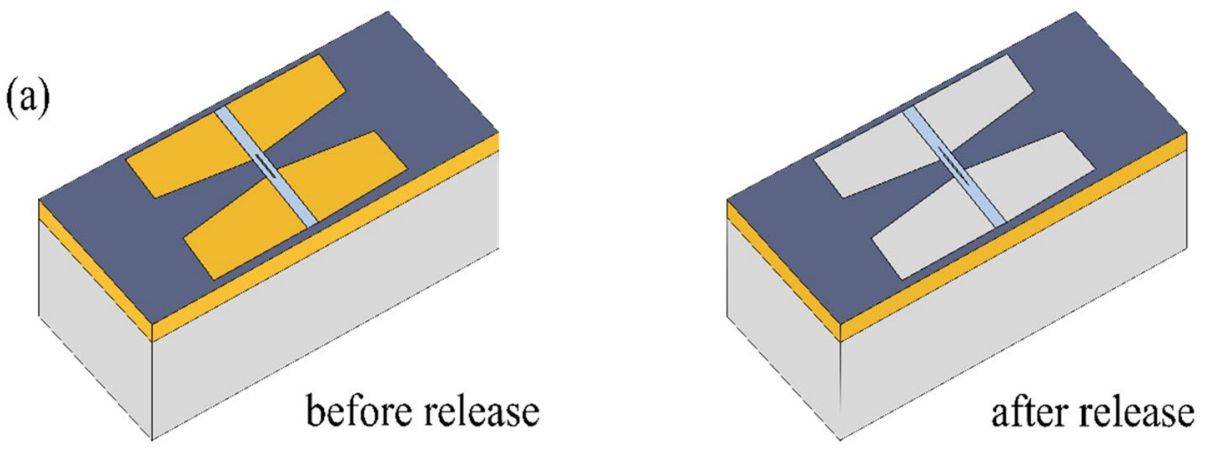

- Si substrate

- Sacrificial layer

- Actuator Specimen

(b)
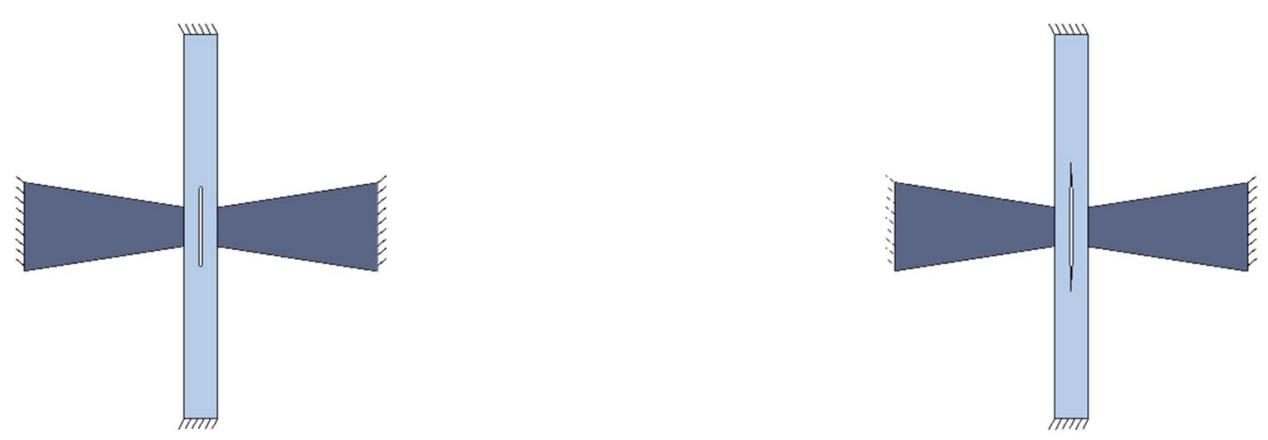

\section{before release}

\section{after release}

Figure 1: Schematic representation of the crack-on-a-chip test configuration and working principle. (a) 3D view of a crack-on-a-chip elementary test specimen, on the left-hand side before etching the sacrificial layer (shown in yellow color) and on the right-hand side after the removal of the sacrificial layer. (b) Zoom of test structures before (right) and after (left) release showing the crack advance and arrest after releasing of the internal stress inside the actuators (shown in dark blue).

and as sacrificial release layers. $\mathrm{SiO}_{2}$ exhibits a high etching selectivity with respect to polysilicon in both hydrofluoric acid (HF) and buffered hydrofluoric acid (BHF). $\mathrm{SiO}_{2}$ is one of the few materials allowed inside polysilicon or silicon nitride ( $\mathrm{SiN}$ ) furnaces. Understanding stress corrosion cracking in $\mathrm{SiO}_{2}$ is also essential for properly interpreting the slow crack propagation appearing in silicon (Si). Indeed, subcritical cracking or fatigue cracking of $\mathrm{Si}$ is sometimes attributed to an environmentally assisted crack growth within the native $\mathrm{SiO}_{2}$ grown on top of Si [19], even though other theories attributing the subcritical cracking to the Si itself [20]. Finally, it is interesting to investigate differences between the thin film and bulk $\mathrm{SiO}_{2}$ as a way to verify our understanding of how size and surfaces affect the deformation and cracking mechanisms.

There is a large amount of data available about stress corrosion cracking in bulk glasses and a good understanding of the underlying physico-chemicomechanical phenomena. Since pioneering works by Grenet [21] and further works by Charles [22] and others, e.g., Wiederhorn $[1,23]$, the origin of slow crack growth by fracture of $\mathrm{Si}-\mathrm{O}-\mathrm{Si}$ bonds near the crack tip has been unraveled. Water molecules forming $(\mathrm{Si}-\mathrm{OH})$ bonds that repel each other result in the opening of pre-existing flaws accompanied by surface energy reduction $[24,25]$. The work of Hatty et al. [11] is, to our knowledge, the only systematic study dealing with environmental crack growth in freestanding $\mathrm{SiO}_{2}$ films reported in the literature. The studied $\mathrm{SiO}_{2}$ film was $1 \mu \mathrm{m}$ thick and deposited by PECVD. The fracture toughness is equal to $0.77 \pm 0.15 \mathrm{MPa}$, similar to the bulk silica value [26]. In contrast, the fracture strength $(0.81 \pm 0.06$ $\mathrm{GPa})$ is an order of magnitude higher than bulk silica $(\sim 0.1 \mathrm{GPa})$ thanks to smaller flaw sizes. Crack growth rates of $9.3 \times 10^{-11}$ to $2.9 \times 10^{-10} \mathrm{~m} / \mathrm{s}$ were measured in laboratory air, smaller than in bulk fused silica for similar $K$ likely due to the differences in chemistry between the $\mathrm{SiO}_{2}$ thin film and bulk silica. Other data can be found in the literature such as the one provided by $\mathrm{Ma}$ [27] or by [28-32] using a four-point bending technique on $\mathrm{SiO}_{2}, \mathrm{SiO}_{2} / \mathrm{TiN}$, and organosilicate glass thin films on a substrate with the difficulties discussed above regarding possible substrate effects.

The outline of the paper is the following. The design and fabrication steps are presented first insisting on the new extensions and the specific implementation to $\mathrm{SiO}_{2}$ films. The results and discussions are combined in the next section addressing successively the static fracture toughness measurements and then the subcritical crack growth rate measurements. The paper ends up with conclusions and perspectives. 


\section{Design and fabrication of the crack-on-chip test}

\section{Finite element modeling}

FE simulations have been performed using the commercial software Abaqus [12] in order to guide the design of the test structure, to analyze the kinetics of the release process, and to establish an accurate data reduction scheme for extracting the mode I stress intensity $K_{\mathrm{I}}$ as a function of the crack length and other geometrical dimensions. Details can be found in [12] and only the main aspects are summarized hereafter, in particular regarding the simulation of the release process, which has been significantly enhanced compared to the original work.

A test structure involving the test sample, the two actuator beams, and a sufficiently wide zone of the surrounding substrate is meshed using 4-node bilinear plane stress elements with reduced integration (CPS4R). The collapsed quadrilateral quarter element technique is used to capture the singularity field near the crack tip in order to extract accurate values of $K_{\mathrm{I}}$. Compared with the earlier study, careful attention has been paid to the overetching of the anchoring regions, which contributes to the establishment of the force equilibrium due to the release of an extra layer to which the specimen and actuators are attached, hence affecting the magnitude of $K_{\mathrm{I}}$. All nodes are initially fixed to mimic the adhesion to a rigid substrate. Linear isotropic elastic Hooke's law is invoked for both the specimen and actuator materials with, respectively, Poisson ratio, $v$ and $v_{\mathrm{a}}$, and Young's modulus, $E$ and $E_{\mathrm{a}}$.

The first step of the calculation consists of a fictitious thermal loading $\Delta T$ applied in order to generate an equibiaxial internal stress field of magnitude

$$
\sigma^{\text {int }}=\frac{E}{1-v} \alpha \Delta T \quad \sigma_{\mathrm{a}}^{\text {int }}=\frac{E_{\mathrm{a}}}{1-v_{\mathrm{a}}} \alpha_{\mathrm{a}} \Delta T_{\mathrm{a}}
$$

for the specimen and actuator, respectively. The magnitude of the stress level in both the test and actuator materials can be imposed by varying either the fictitious thermal expansion exponent $\alpha$ or by imposing a different $\Delta T$ in the two materials.

The second step is the release of the test structure. The nodes are progressively released over time according to their shortest distance to one of the nodes located at the edges of the geometry. These nodes are at the interface between the structure and the Si cavities from where the etchant can reach easily the silicon beneath the structure, making these nodes (called "contour nodes") easier to be released. The node is released when the minimum calculated distance associated with a node is larger than the product of etching rate and time. The release is stopped when the final etching $t_{\mathrm{f}}$ time is attained, leaving several nodes at the periphery of the model unreleased, hence dictating the clamping frontier.
As the materials are both linear elastic, the sequencing and the dynamics of the release process does not matter here. This means that different crack lengths can be addressed using the same strategy and that we do not have to take into account a specific time duration to calculate the $K$ value corresponding to different crack lengths (resulting from a slow crack growth process continuing well after the release). This would obviously not be correct when treating viscoelastic materials responses for instance. The $K$ value is directly provided by the code from $J$-integral values calculated based on the interaction integral method of Shih and Asaro [33]. Careful convergence analysis has been performed to ensure that the results were independent of the level of mesh refinement.

Besides, an assessment of the model has been conducted based on the comparison between the notch opening measured experimentally from high magnification scanning electron microscopy (SEM) images and the one extracted by FE simulations for a large number of devices. Finally, a 3D version of the FE model has also been built to investigate the effect of the outof-plane displacement on the extracted value of $K_{\mathrm{I}}$, as reported in the Supplementary Materials.

\section{Crack-on-chip test configurations: new designs}

Compared with the first generation of test structures briefly presented in the introduction [12], several new extensions have been worked out in order to solve some of the problems related to the original designs. The panel of Fig. 2a-f illustrates the problems of the first generation and solutions proposed for the second generation based on SEM micrographs of real test structures, for different types of thin film materials $\left(\mathrm{SiN}, \mathrm{SiO}_{2}\right.$, $\mathrm{Al}_{2} \mathrm{O}_{3}$ ). These micrographs have been taken after release, showing some degree of crack propagation. The analysis of the crack propagation results is left to "Validation of the new designs and enhanced reduction scheme" section.

In [12], all reported experimental data were obtained with an asymmetric design. The asymmetric design shown in Fig. 2a consists of two actuator beams pulling on a specimen with a notch at the edge, resembling the classical double cantilever beam (DCB) configuration. One of the main shortcomings of this design is the possible generation of large out-of-plane displacements of the actuator beam caused by their low bending stiffness. Often one beam displaces out of a plane more than the other due to small misalignments or imperfections, leading to an uncontrolled mode III contribution to the crack driving force and the measured crack resistance. The symmetric configuration is the natural choice to limit this effect. The symmetric design shown in Fig. $2 \mathrm{~b}-\mathrm{f}$ is similarly made of two actuator beams pulling on a specimen containing a central notched slit, as shown in Fig. $2 \mathrm{~b}$ for $\mathrm{SiN}$ beams pulling on a $\mathrm{SiO}_{2}$ notched film. The analytical, as well 
(a)

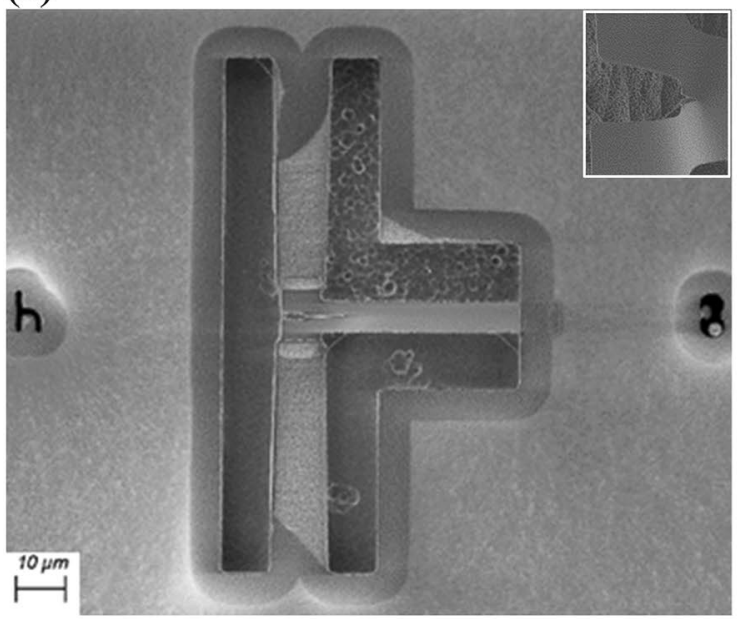

(c)

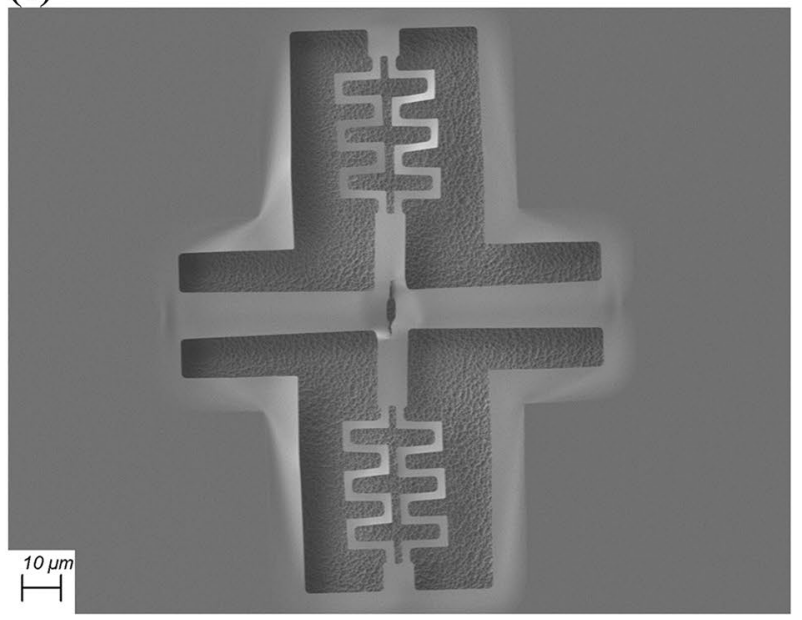

(b)

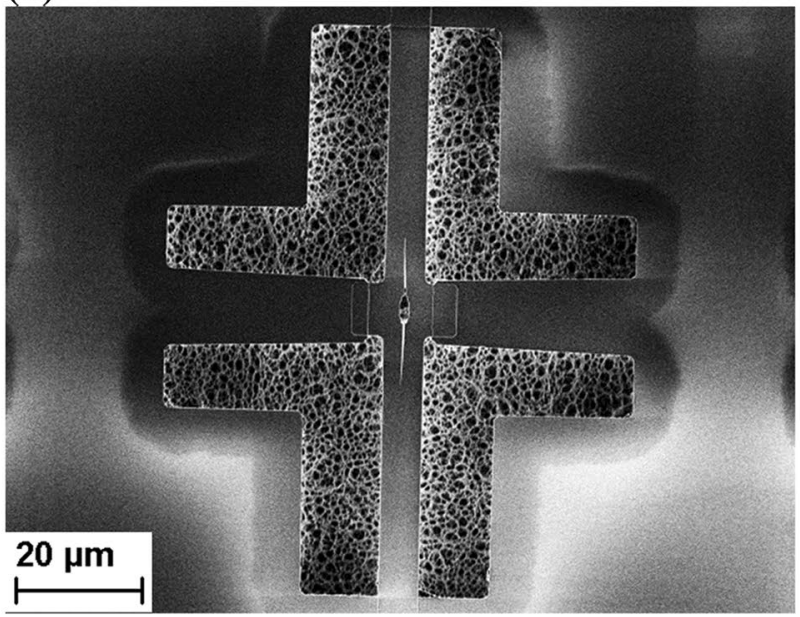

(d)

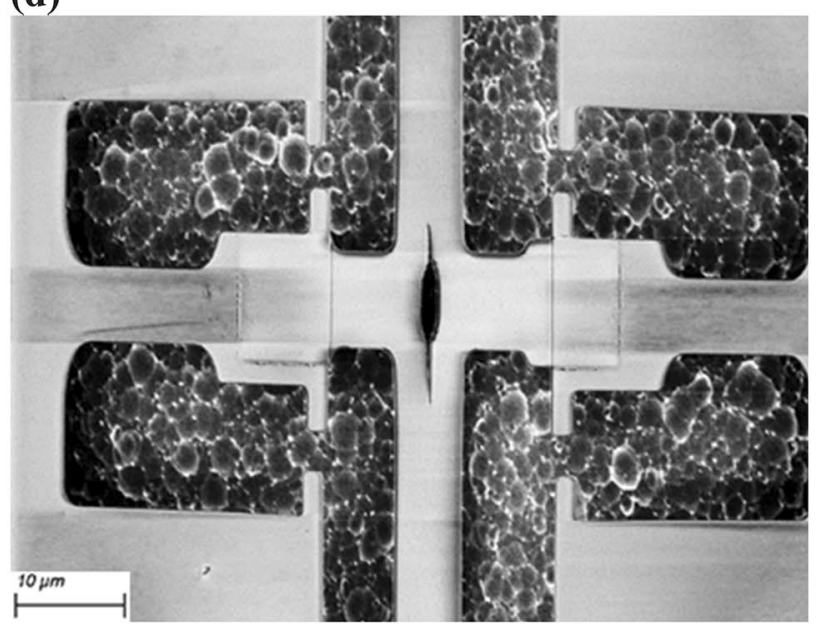

(e)

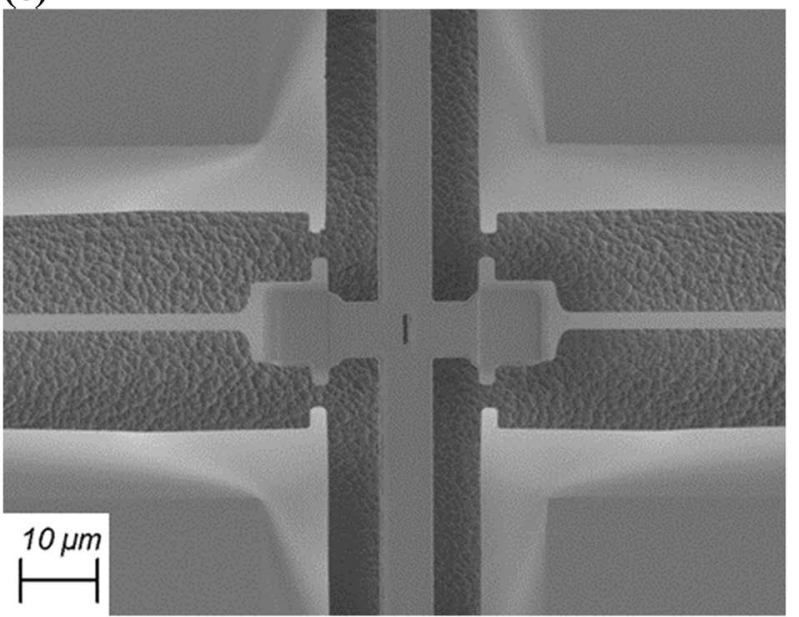

(f)

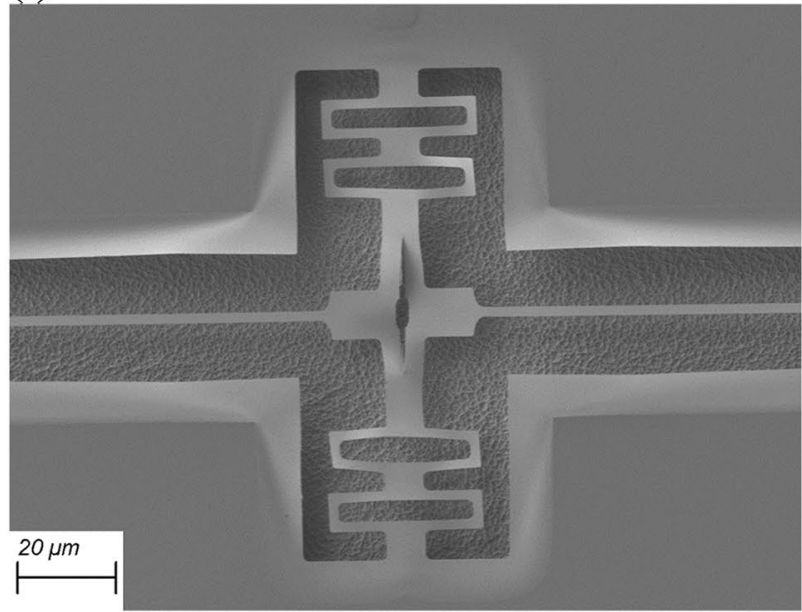

Figure 2: Different crack-on-a-chip test configurations with recent enhancements. (a) Original asymmetric design for $\mathrm{SiO}_{2}$ and the inset illustrates out-of-plane distortion for a Ni thin film specimen, (b) symmetric design for $\mathrm{SiO}_{2}$, (c) symmetric design with spring at specimen ends to reduce the transversal stress component and crack kinking for $\mathrm{SiN}_{\mathrm{N}}(\mathrm{d})$ cross-section reduction along the overlap to avoid fracture and cursors to measure the specimen opening for thin $\mathrm{Al}_{2} \mathrm{O}_{3}$ film, (e) "unloading" design to release the actuator before the specimen of $\mathrm{Al}_{2} \mathrm{O}_{3}$, and (f) "unloading" symmetric autoactuated test configuration of SiN films with springs showing straight crack propagation, but some mode III component. 
as the numerical analysis of the symmetric configuration, was already addressed in [12] but it was not yet implemented in real experiments and the overetching effect was not taken into account. The validation of the effectiveness of the symmetric design for reducing the mode III component is discussed in "Validation of the new designs and enhanced reduction scheme" section.

The second shortcoming of the original design was the repeated observation of cracks kinking out of the specimen (sometimes breaking the specimen before any arrest) and not propagating straight ahead. The origin of this crack kinking was due to the presence of tensile internal stress in the test specimen. In reference [12], tests were performed on self-actuated SiN films with $1 \mathrm{GPa}$ tensile stress component. A very small deviation of the crack out of the straight path was then amplified by the internal tensile stress component parallel to a straight path, inducing the crack kinking at $90^{\circ}$ in order to maximize the mode I component. The problem of the transverse internal stress is amplified with the symmetric design as in this case the specimen is attached on both ends, not allowing any relaxation of this stress component. To reduce the internal stress component parallel to the crack propagation direction, a new design has been worked out with each specimen ending with a spring-type connector as shown in Fig. $2 \mathrm{c}$ for a SiN test specimen.

Dealing with a specimen material different from the actuator layer brings about additional difficulties related to the stress concentration at the overlap between the actuator beam and specimen. Many examples of specimen fracture were observed during preliminary tests on $\mathrm{Cu}$ and $\mathrm{Ni}$. The introduction of a dog-bone type reduction of the section near the overlap is the natural way to reduce the stress at the overlap. FE modeling using Abaqus software was performed to guide the selection of the appropriate dog-bone shape, as shown in Fig. $2 \mathrm{~d}$ for an $\mathrm{Al}_{2} \mathrm{O}_{3}$ specimen.

In general, as shown in Fig. $2 \mathrm{a}-\mathrm{d}$, the actuator beams are wider than the test specimen and also tapered. This ensures a progressive release of the actuator with the test specimen, already released, hence progressively loaded. In Fig. 2e, one extra specific design where the actuator is narrower than the cracked specimen is proposed. This new configuration is such that the actuator beams are released first followed by the test specimen, unloading the latter and hence called unloading structures (this variant makes sense for test specimens containing large internal stresses only). Both symmetric and asymmetric configurations have been addressed with this design. This kind of configuration allows applying a very small displacement that is useful when the specimen requires only a small load to initiate cracking. Moreover, these actuators lead to a smaller measurement error if the overetching is not well taken into account since they are longer. The unloading structures combined with a spring design were also tested as shown in Fig. $2 \mathrm{f}$ for a SiN specimen.
Finally, as explained in "Finite element modeling" section, we also extended the analysis to properly account for the effect of overetching of the anchoring regions as discussed later, which can be observed in Fig. 2 all taken after release, as well as the unbalanced out-of-plane displacement of the actuator beams.

Each design of the aforementioned configurations was developed to correct some specific drawbacks coming from the original non-optimized designs, but these drawbacks vary from one sample to another dictating the use of one of the proposed designs.

\section{Fabrication of crack-on-chip for $\mathrm{SiO}_{2}$ film testing}

Details of the fabrication process of crack-on-a-chip test structures are given in the "Methods" section. Figure 3 summarizes the fabrication flow with the specific implementation for the testing of $\mathrm{SiO}_{2}$ cracked specimens. The process was inspired from the previous applications made with the UCLouvain onchip test method [12-18] but with some changes. For instance, the test specimen material $\mathrm{SiO}_{2}$ in the present work is deposited here before the actuator material contrary to the previous works [12-18].

The uncertainties on the geometrical and mechanical parameters were estimated as summarized in Table 1. These uncertainties on each parameter all affect the level of accuracy of the extracted value of $K_{\mathrm{Ic}}$, but different degrees. The relative error on stress intensity factor $K_{I}$ is determined using the propagation of uncertainties method [34] as explained in more detail in the Supplementary Materials.

\section{Results and discussion}

\section{Validation of the new designs and enhanced reduction scheme}

For the sake of validating first the accuracy of the FE simulations, Fig. 4 compares the notch opening measured experimentally to the simulated value, based on all the parameters determined as explained earlier. If the structure involves a crack initiated from the notch tip, this crack is taken into account in the simulations with a length equal to the experimental crack length (there is no fracture model involved in these calculations). The difference remains below $3 \%$, which is a very good result in view of the uncertainties described above, probably indicating that our estimates of the uncertainties are true upper bounds (these calculations take also into account the sacrificial layer overetch, which definitely plays a significant role to generate accurate predictions, see further).

Figure $2 \mathrm{~b}$ shows a significant reduction of the out-of-plane displacement compared with Fig. 2a, where the inset shows considerable out-of-plane distortion in a $\mathrm{Ni}$ cracked specimen. This does not mean that out-of-plane displacements are never 

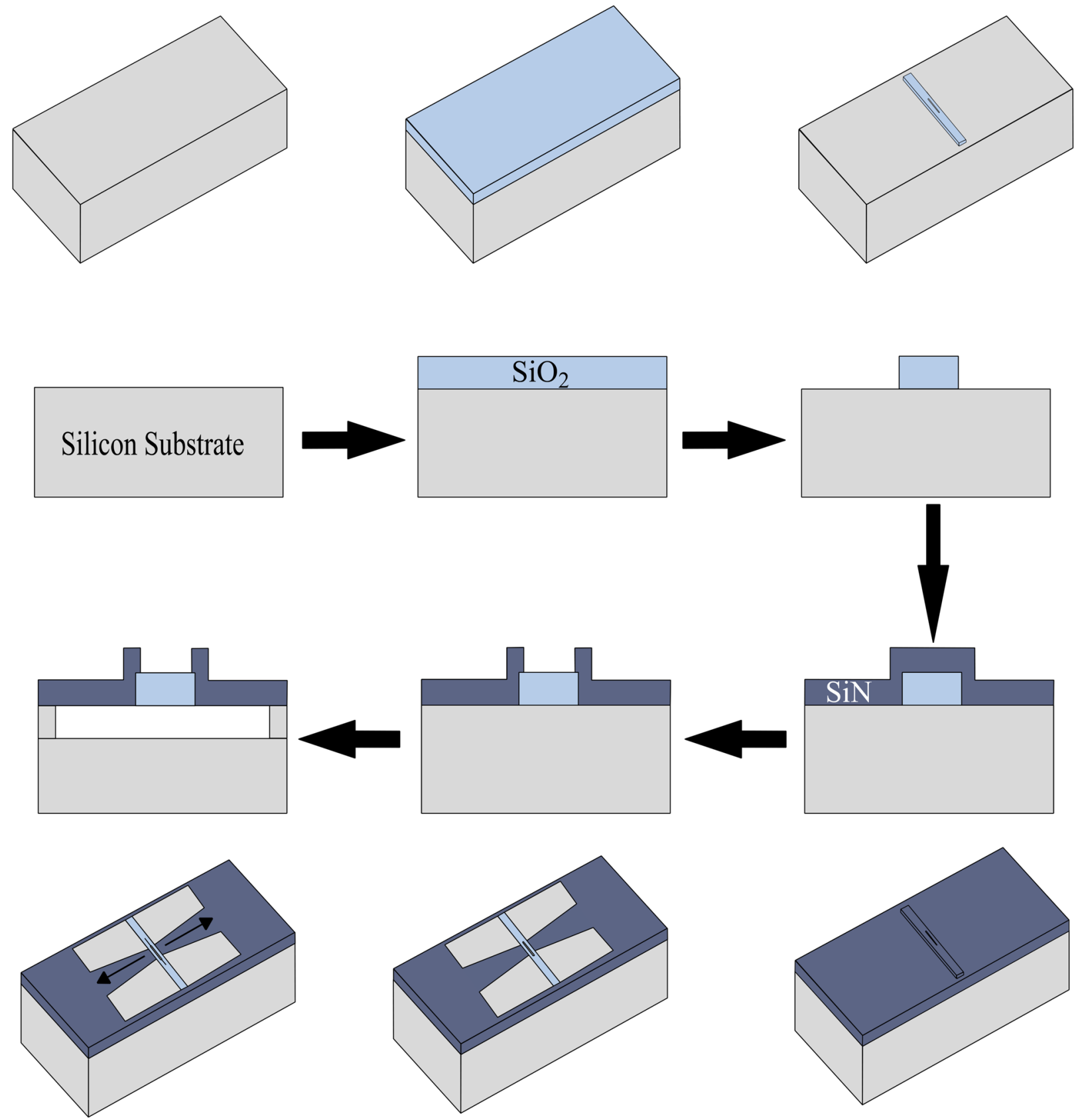

Figure 3: Fabrication process steps adjusted for crack-on-a-chip of $\mathrm{SiO}_{2}$. The first deposition is made for the sample (light blue) followed by the actuator layer (dark blue).

observed in the symmetric configuration, as seen in Fig. $2 \mathrm{f}$ but they are significantly reduced. A comparison of the test results obtained with the symmetric and asymmetric tests is discussed in the next subsection for the specific application to $\mathrm{SiO}_{2}$ with a focus on the magnitude of the mode III component.

Figure $2 c$ shows an example of a symmetric spring design successfully working for a SiN film (again, see [12] for the details on the fabrication of the SiN test structures). The crack is propagating straight as in most cracked specimens, and this, even if the transverse tensile stress was initially large. Other materials also have been successfully tested with this design.

Failure along the overlap with the actuator sometimes occurs as a result of the local stress concentration combined with insufficient conformity of the film. Problems have been detected for instance when testing $\mathrm{Al}_{2} \mathrm{O}_{3}$ films failing at the overlap. A successful design is shown in Fig. 2d; it consists of $\mathrm{SiN}$ actuator beams pulling on $\mathrm{Al}_{2} \mathrm{O}_{3}$ cracked specimens. 
TABLE 1: Summary of the uncertainties on the parameters required for extraction of the stress intensity factor $K_{1}$.

\begin{tabular}{lll}
\hline \hline Parameter & Measurement method & Uncertainty \\
\hline $\begin{array}{l}\text { Actuator Young's modulus }\left(E_{\mathrm{a}}\right) \\
\begin{array}{c}\text { Specimen Young's modulus } \\
(E)\end{array}\end{array}$ & $\begin{array}{l}\text { Nanoindentation } \\
\text { Nanoindentation }\end{array}$ & $\Delta E_{\mathrm{a}}=8 \mathrm{GPa}$ \\
$\begin{array}{l}\text { Internal stress of the actuator } \\
\left(\sigma_{\mathrm{a}}^{\text {int }}\right)\end{array}$ & Stoney measurement & $\Delta \sigma_{\mathrm{a}}^{\text {int }}=10 \mathrm{GPa}$ \\
$\begin{array}{l}\text { Internal stress of the actuator } \\
\left(\sigma^{\text {int }}\right)\end{array}$ & Stoney measurement & $\Delta \sigma^{\mathrm{int}}=10 \mathrm{MPa}$ \\
$\begin{array}{l}\text { Poisson ratio of the actuator } \\
\left(v_{\mathrm{a}}\right)\end{array}$ & From literature & $\Delta v_{\mathrm{a}}=0.01$ \\
$\begin{array}{l}\text { Poisson ratio of the specimen } \\
(v)\end{array}$ & From literature & $\Delta v=0.01$ \\
Thickness of actuator $\left(t_{\mathrm{a}}\right)$ & Ellipsometry & $\Delta t_{\mathrm{a}}=1 \mathrm{~nm}$ \\
Thickness of specimen $(t)$ & Ellipsometry & $\Delta t=1 \mathrm{~nm}$ \\
Crack length $(a)$ & SEM & $\Delta a=50 \mathrm{~nm}$ \\
Actuator width $\left(W_{\mathrm{a}}\right)$ & SEM & $\Delta W_{\mathrm{a}}=50 \mathrm{~nm}$ \\
Actuator length $\left(L_{\mathrm{a}}\right)$ & SEM & $\Delta L_{\mathrm{a}}=100 \mathrm{~nm}$ \\
Specimen length $(L)$ & SEM & $\Delta L=30 \mathrm{~nm}$ \\
Specimen width $(W)$ & SEM & $\Delta W=30 \mathrm{~nm}$ \\
\hline \hline
\end{tabular}

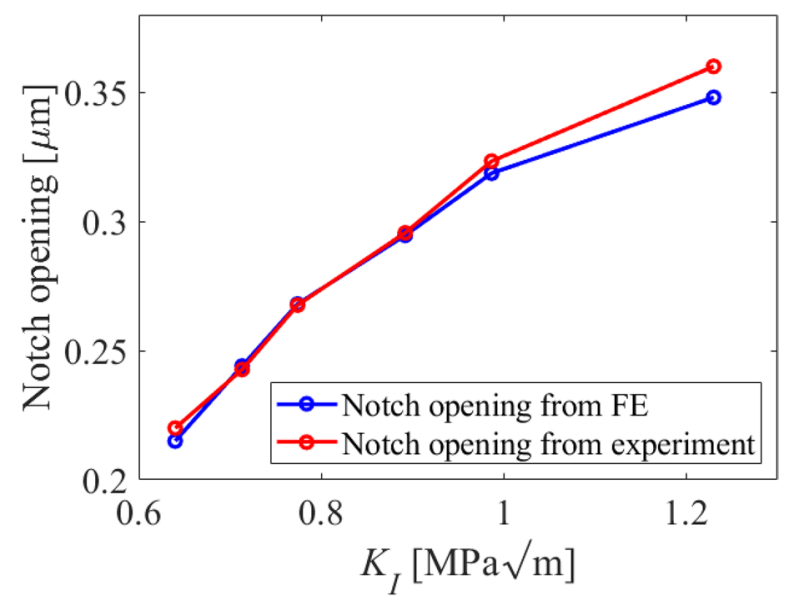

Figure 4: Difference between notch opening given by FE and the experiment for different $K_{\mathrm{I}}$ values.

The progressive release is simulated numerically following the method explained in "Finite element modeling" section and shown in Fig. 5a. One of the difficulties associated with the chemical release process is the overetch of the underlying sacrificial layer systematically occurring at the anchoring sections-as observed in all Fig. 2 of the panel. This overetching contributes to the establishment of the load equilibrium as an effective extra actuator length and thus to a different displacement imposed onto the test specimen. The period of time needed to fully release the structure is at least equal to the half-width of the actuator beam divided by the sacrificial layer etch rate. As a matter of fact, $t_{\mathrm{f}}$ is always a little longer to ensure the full release of the structure. This extra time is labeled as extra-overetching time, even though it is important to realize that overetching of the anchors always occurs from the first second of the release process. For the sake of comparison, simulations have also been performed with no overetching at all, as shown in Fig. 5b, by fixing the end nodes of the actuators and test specimen. Figure $5 \mathrm{c}$ shows the impact of the overetching length on the SIF corresponding to different etching times, compared with an unrealistic release with no overetching (red curve). The effect of the overetching is significant at small actuator lengths. A longer actuator reduces the effect of the overetching length on affecting the magnitude of $K_{\mathrm{I}}$. In the present work, the overetching is systematically accounted for when modeling the experimental test structures.

Finally, the overlap correction to avoid premature fracture at this location has been implemented successfully for the $\mathrm{SiO}_{2}$ films as it will appear in the next sections.

\section{Fracture toughness measurements}

The fracture toughness of the $\mathrm{SiO}_{2}$ films is determined for both the symmetric and asymmetric configurations for crosscomparison. Each die was released to perform the crack length measurements directly after each release in order to have the shortest possible delays. Each die involved hundreds of both symmetric and asymmetric structures with different notch lengths as well as different actuator lengths varying from 10 to $100 \mu \mathrm{m}$. Six dies were used to study the effect of humidity and temperature on subcritical crack growth. The stress intensity factor was systematically extracted through FE simulations following the methodology explained in "Finite element modeling" section. The parameters of the simulations are listed in Table 2.

Only test structures showing straight crack paths were taken into account in the statistical analysis. A total of 257 structures showed a perfectly linear crack arrest length. The crack arrest lengths measured directly after release were considered as providing a good approximation of the fracture toughness (a basic extrapolation of the crack growth rates described in the next section show that this procedure underestimates the $K$ value by less than $0.02 \%$ ).

Figure 6 presents the cumulative probability of fracture toughness corresponding to the asymmetric and the symmetric configuration. The results coming from six dies are used to generate these data. The results coming from each die separately are provided in the Supplementary Materials (Fig. S1), showing the good reproducibility of the measurements from die to die. The number of structures exhibiting perfectly straight crack varies from one die to another; for instance, in the symmetric structures, die 2 had only 12 valid cracked specimens, while die 6 had 38. Table 3 summarizes the statistical data presented in Fig. 6 as well as the data for each die. There is a clear systematic 
(a)

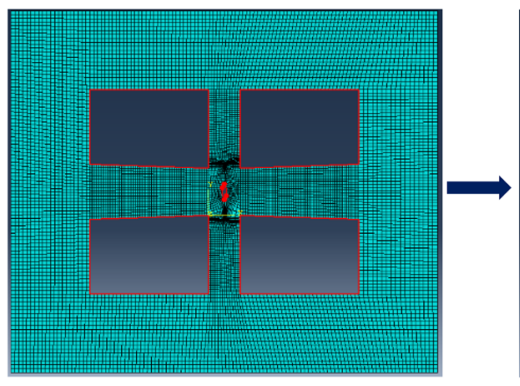

(b)

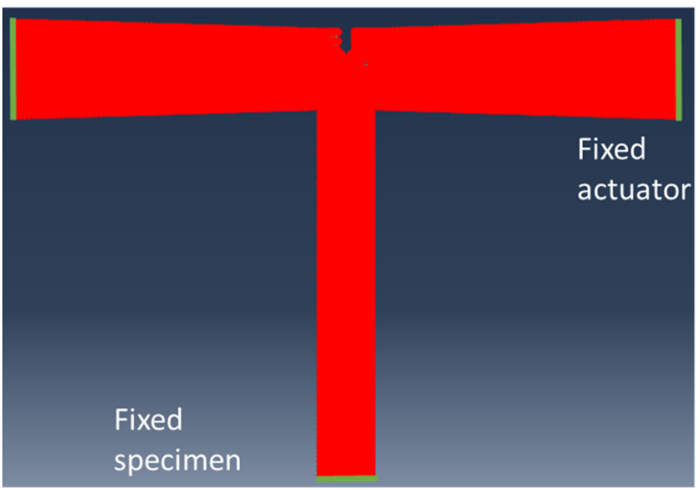

specimen

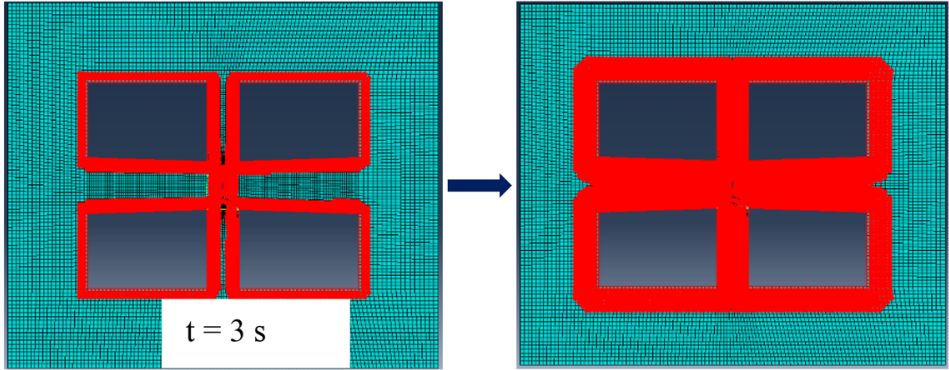

$\mathrm{t}=7 \mathrm{~s}$

(1 s overetching time)

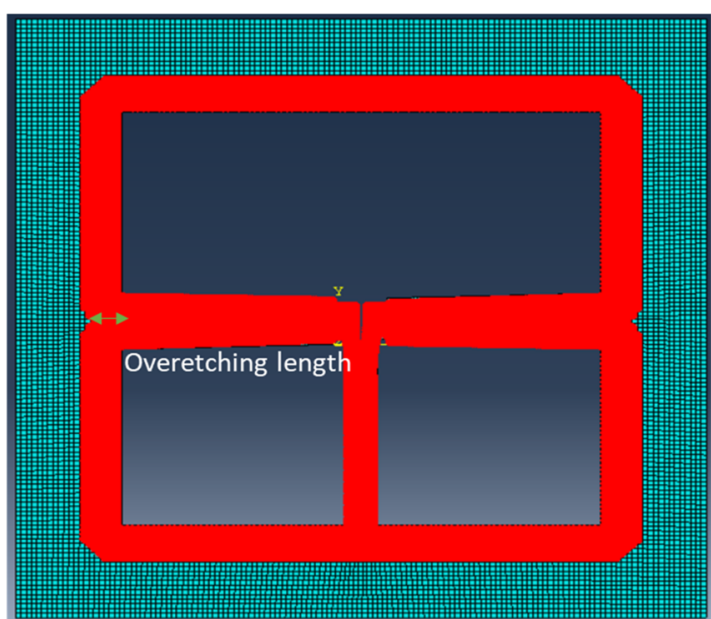

( $2 \mathrm{~s}$ overetching time)

(c)

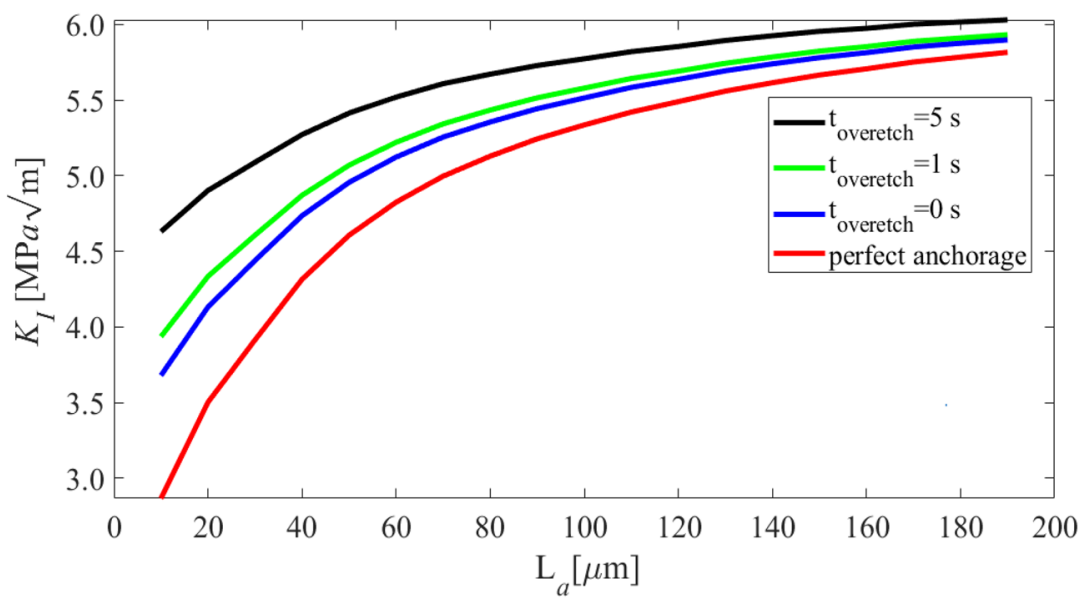

Figure 5: (a) FE modeling of the progressive release of the specimen at different time intervals. Nodes are released progressively according to their proximity to the contour (red edges in the left image). (b) Comparison between conditions with overetching and with no overetching at all, the first schematic presents the instantaneous release where the released nodes are in red and the green color shows the fixed edges. Right drawing presents the progressive release with overetching, the blue are the nodes that are anchored. (c) Variation of $K_{l}$ as a function of actuator length $L_{a}$ for different release scenarios. In the release with no overetching, all the nodes are released at once except the edges of the specimen and actuator that are fixed. 
TABLE 2: Mechanical and geometrical parameters used in the FE simulations for $\mathrm{SiO}_{2}$ specimens.

\begin{tabular}{ll}
\hline \hline Young's modulus of test material $E$ & $70 \mathrm{GPa}$ \\
Poisson ratio of test material $v$ & 0.17 \\
Young's modulus of actuator $E_{\mathrm{a}}$ & $225.5 \mathrm{GPa}$ \\
Poisson ratio of actuator $v_{\mathrm{a}}$ & 0.28 \\
Internal of test material & $-340 \mathrm{MPa}$ \\
Internal of actuator material & $1.1 \mathrm{GPa}$ \\
Notch radius & $1.2 \mu \mathrm{m}$ \\
Notch length & 0 to $24 \mu \mathrm{m}$ with $1 \mu \mathrm{m}$ increments \\
Actuator length $L_{\mathrm{a}}$ & 10 to $100 \mu \mathrm{m}$ with $2 \mu \mathrm{m}$ increments \\
Actuator width $W_{\mathrm{a}}$ & $10 \mu \mathrm{m}$ \\
Specimen width & $7.7 \mu \mathrm{m}$ \\
Total release time $t_{\mathrm{f}}$ & 10 to $12 \mathrm{~s}$ \\
\hline \hline
\end{tabular}

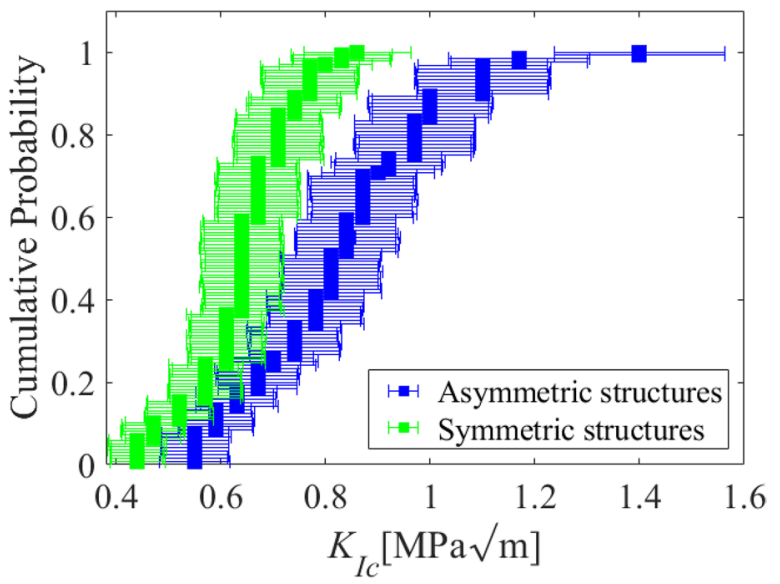

Figure 6: Probability distribution of fracture toughness for symmetric and asymmetric geometries. trend for the symmetric test structures to deliver fracture toughness values $25-30 \%$ lower than the asymmetric configuration. More precisely, in the asymmetric structures, $K_{\mathrm{Ic}}$ varies between $0.55 \pm 0.07$ to $1.4 \pm 0.16 \mathrm{MPa} \sqrt{\mathrm{m}}$, while in symmetric structures, $K_{\mathrm{Ic}}$ varies between $0.44 \pm 0.06$ to $0.86 \pm 0.1 \mathrm{MPa} \sqrt{\mathrm{m}}$. For each released die the mean and the most probable value of $K_{\mathrm{Ic}}$ are determined for both symmetric and asymmetric configurations. The most frequent $K_{\mathrm{Ic}}$ is the value that has the highest probability in each die. It is determined at the maximum derivative point. Table 3 also provides the mean and most probable values for all the dies taken together.

The artifacts and possible uncertainties or errors affecting the analysis are the following: (i) the release process is not exactly similar from one die to another since each release is performed manually affecting the amount of $\mathrm{XeF}_{2}$ and thus the length of the overetched part (now accounted for in the analysis in which only one overetched length is imposed); (ii) inaccuracies are involved in the measurement of the crack length as well as of other geometrical parameters (see Table 1); (iii) inaccuracies are involved in the determination of the elastic properties and internal stress level (see Table 1); (iv) the contribution of the mode III component varies from one structure to another due to small imperfections; (v) the test material may show internal variations of structure (composition, free volume, defects) over the wafer and thus from one specimen to another, or from one series of specimens to another; (vi) small variation of the notch front shape can occur due either to the release or to the lithography; (vii) during the same test, the release is not perfectly homogenous leading to non-symmetric and inhomogeneous release edges also sometimes with a few material regions still

TABLE 3: Experimental fracture toughness $K_{\mathrm{lc}}$ results for $\mathrm{SiO}_{2}$ thin films for different released dies.

\begin{tabular}{|c|c|c|c|c|}
\hline & $\begin{array}{c}\text { Asymmetric structures } \\
\text { number }\end{array}$ & $\begin{array}{c}\text { Symmetric structures } \\
\text { number }\end{array}$ & Mean value of $K_{\mathrm{lc}}(\mathrm{MPa} \sqrt{\mathrm{m}})$ & Most frequent $K_{\mathrm{Ic}}(\mathrm{MPa} \sqrt{\mathrm{m}})$ \\
\hline Die 1 & 16 & - & $0.8 \pm 0.04$ (asym) & $0.74 \pm 0.09$ (asym) \\
\hline \multirow[t]{2}{*}{ Die 2} & 22 & 12 & $0.91 \pm 0.03$ (asym) & $0.86 \pm 0.1$ (asym) \\
\hline & & & $0.6 \pm 0.01$ (sym) & $0.56 \pm 0.07(\mathrm{sym})$ \\
\hline \multirow[t]{2}{*}{ Die 3} & 13 & 20 & $0.86 \pm 0.04$ (asym) & $0.74 \pm 0.09$ (asym) \\
\hline & & & $0.61 \pm 0.03$ (sym) & $0.6 \pm 0.07(\mathrm{sym})$ \\
\hline \multirow[t]{2}{*}{ Die 4} & 20 & 31 & $0.76 \pm 0.05$ (asym) & $0.56 \pm 0.07$ (asym) \\
\hline & & & $0.66 \pm 0.02$ (sym) & $0.65 \pm 0.08$ (sym) \\
\hline \multirow[t]{2}{*}{ Die 5} & 26 & 36 & $0.86 \pm 0.04$ (asym) & $0.59 \pm 0.07$ (asym) \\
\hline & & & $0.68 \pm 0.01$ (sym) & $0.66 \pm 0.08(\mathrm{sym})$ \\
\hline \multirow[t]{2}{*}{ Die 6} & 23 & 38 & $0.77 \pm 0.03$ (asym) & $0.66 \pm 0.08$ (asym) \\
\hline & & & $0.61 \pm 0.01$ (sym) & $0.57 \pm 0.07$ (sym) \\
\hline \multirow[t]{2}{*}{ All asymmetric structures } & 120 & - & $0.83 \pm 0.02$ & $0.74 \pm 0.09$ \\
\hline & & & $S D= \pm 0.17$ & \\
\hline \multirow[t]{2}{*}{ All symmetric structures } & - & 137 & $0.64 \pm 0.008$ & $0.64 \pm 0.08$ \\
\hline & & & $S D= \pm 0.09$ & \\
\hline \multirow[t]{2}{*}{ All structures } & 257 & & $0.73 \pm 0.01$ & $0.64 \pm 0.08$ \\
\hline & & & $S D= \pm 0.17$ & \\
\hline
\end{tabular}


attached to the substrate, which vary from one test specimen to another and which are not taken into account in the FE modeling. The effects that can be taken into account are (i) to (iii), with a specific additional analysis later for (iv). A detailed error propagation has been conducted to quantify the effect of the sources of uncertainty (on the precision of the extraction of $K_{\mathrm{Ic}}$ value, see Supplementary Materials). Two main types of errors are defined, constant systematic error (same for each structure) and variable errors that vary from one structure to another. The error in the best case is around $11 \%$ and can reach up $12.3 \%$.

The expected initial reason for the difference between the asymmetric and symmetric structures is the difference in the out-of-plane displacements, as related to a reduction of the mode III component. This was the underlying motivation for introducing a symmetric design. The contribution of mode III has been investigated using 3D FE simulations by enforcing an out-of-plane displacement that is similar to the one observed experimentally. The details are given in the Supplementary Materials. The preliminary simulations show that $K_{\mathrm{III}}$ is never larger than $3 \%$ of $K_{\mathrm{I}}$ in the worst case of asymmetric structures (Fig. S2 of the Supplementary Materials). However, deeper investigation is needed in order to consolidate these results, which were obtained by imposing the out-of-plane displacements and not by inducing them "naturally" through imperfections in the geometry and in the release. This result indicates that either the FE analysis misses the impact of some additional overall relaxation of the asymmetric structures due to warping, or that there is an extra effect not yet properly quantified to explain the differences between the mean values extracted from both types of geometries. One option is the larger systematic errors associated with the asymmetric structures, mentioned above. However, the key point is that the symmetric design remains much more planar and thus less prone to overall instabilities compared to the asymmetric one. The narrower fracture toughness distribution in the symmetric structure is also an indicator of a more robust design.

Nevertheless, the fact that the fracture toughness, even for the symmetric structures, is distributed over a range of values, which is larger than the overall estimated error bars means either that some of the other sources of uncertainty play a role, or that we have underestimated one effect in the error analysis. Further analysis is needed to analyze possible true variations of the material structure (iv) from one test structure to another, but this requires relatively long characterization.

Considering only the asymmetric structures leads to a mean value of $K_{\mathrm{Ic}}$ equal to $0.83 \pm 0.02 \mathrm{MPa} \sqrt{\mathrm{m}}$. The mean value for the symmetric structures is equal to $0.64 \pm 0.008 \mathrm{MPa} \sqrt{\mathrm{m}}$. The mean $K_{\mathrm{Ic}}$ for all test structures is equal to $0.73 \pm 0.01 \mathrm{MPa} \sqrt{\mathrm{m}}$ and the most frequent value is equal to $0.64 \pm 0.08 \mathrm{MPa} \sqrt{\mathrm{m}}$. The latter value is also the most frequent as well as the mean value of all the symmetric designs. It is worth noting that the uncertainty of the measurement of the mean value was obtained using the standard error (SE) notion. However, as explained above, the error bar corresponding to one measurement was determined following the error propagation method described in detail in the Supplementary Materials. The standard deviation (SD) value is also determined in order to clarify the dispersion in the obtained fracture toughness values (see Table 3). A higher distribution was observed in the asymmetric designs in which a standard deviation of $0.17 \mathrm{MPa} \sqrt{\mathrm{m}}$ was determined compared with symmetric designs that lead to almost half of this value $0.09 \mathrm{MPa} \sqrt{\mathrm{m}}$. The same value was obtained when both configurations are grouped together. The SD value is large compared with the measured errors coming from the technique itself. Hence, this large range of fracture toughness cannot be due to experimental uncertainties. The reason of the observed scattering of $K_{\mathrm{Ic}}$ data remains which is partly unclear.

The mean value $0.73 \pm 0.01 \mathrm{MPa} \sqrt{\mathrm{m}}$ is slightly smaller compared with the bulk silica value of $0.79 \pm 0.01 \mathrm{MPa} \sqrt{\mathrm{m}}[26]$ and compares very well with the value $0.77 \pm 0.15 \mathrm{MPa} \sqrt{\mathrm{m}}$ obtained for $1 \mu \mathrm{m}$ thick PECVD $\mathrm{SiO}_{2}$ films [11]. Note that in the work of Hatty et al. [11], the $K_{I C}$ is overestimated since it is estimated from an upper and lower bound, and since their design is similar to the asymmetric designs of this present work hence involving some amount of out-of-plane displacement. Therefore, a comparison between the mean $K_{\mathrm{Ic}}$ deduced from asymmetric structures and [11] is probably more relevant.

\section{Subcritical crack growth}

The influence of the humidity and the temperature on the crack growth rate in the $\mathrm{SiO}_{2}$ films presented in the last section has been investigated by storing the six dies under the following environmental conditions: (i) in laboratory air with around $40 \%$ relative humidity $(\mathrm{RH})$ and $20^{\circ} \mathrm{C}$, (ii) inside nitrogen $\mathrm{N}_{2}$ desiccator at about $20^{\circ} \mathrm{C}$, (iii) inside a humidity chamber under $60 \%$ $\mathrm{RH}$, at $20^{\circ} \mathrm{C}$ and $80^{\circ} \mathrm{C}$, (iv) inside a humidity chamber under 95\% RH, at $20^{\circ} \mathrm{C}$ and $80^{\circ} \mathrm{C}$.

After the release of each die, the crack length was measured based on high magnification SEM images before being transferred into the environmental chamber. The sample was then removed, after different time intervals, from the chamber and the measurement of crack growth was performed as fast as possible before being returned to the chamber. This operation was carried out at least 8 times, by increasing the duration of storage in each test (anticipating an Arrhenius type evolution). The influence of the environment on the crack growth rate was studied over typically 20 to 30 structures for each condition. Once again, these measurements are only possible because of the stable nature of the geometry used in this research, which induces a decrease of $K$ as the crack propagates. 
The procedure to extract the crack growth rate is the following. The crack growth rate is determined by taking the slope of the $a-t$ curves corresponding to each structure between two time intervals $t_{i}$ and $t_{i+1}$ and by taking the $K$ value corresponding to the mean crack length during that time interval $a_{\text {imean }}=\left(a_{i}+a_{i+1}\right) / 2$. Then, all da/dt obtained for the same range of values of $K_{\mathrm{I}}$ (within a range of $\pm 0.05 \mathrm{MPa} \sqrt{\mathrm{m}}$ ) are averaged to generate the final evolutions, aggregating thus many test structures to reduce the dispersion.

Figure 7 shows the variation of the crack rate growth rate as a function of the stress intensity factor $K_{\mathrm{I}}$ under the aforementioned environmental conditions for both symmetric and asymmetric geometries. Note first that no results are given with the symmetric structures for the dry $\mathrm{N}_{2}$ and ambient air tests, as these test structures were not yet optimized at the time of these first tests. Figure 7a corresponds to asymmetric structures subjected to dry $\mathrm{N}_{2}$ and ambient air showing 100 times faster rates with humidity. Figure $7 \mathrm{~b}-\mathrm{d}$ provides the crack extension rates for both symmetric and asymmetric structures as well as the master curve giving the average crack rate of both configurations (green). Figure 7e shows the variation of the crack growth rate as a function of $K_{\mathrm{I}}$ obtained from the asymmetric structures that were able to resist without failure under high temperature and humidity levels, $95 \% \mathrm{RH}$ and $80^{\circ} \mathrm{C}$. After 5 min under these severe conditions, just three asymmetric structures survived, from which useful information could be extracted. Moreover, under the same humidity conditions, the crack growth rate increased by one order of magnitude when the temperature was increased from 20 to $80^{\circ} \mathrm{C}$. Some of the test structures did not show any crack initiation and arrest before being subject to environmental conditions, which then triggered the cracking process especially at very high temperatures under both $60 \%$ and $95 \% \mathrm{RH}$. This is why more points are shown in these figures than addressed in the last section on static fracture.

All results are summarized in Fig. $7 \mathrm{f}$ which also incorporates data from the literature. We find a crack growth rate of $(2.6 \pm 0.67) \times 10^{-9} \mathrm{~m} / \mathrm{s}$ corresponding to a value of $K_{\mathrm{I}}=0.62 \pm 0.07 \mathrm{MPa} \sqrt{\mathrm{m}}$ under $95 \% \mathrm{RH}$ and $20^{\circ} \mathrm{C}$, which is one order of magnitude higher than the rate measured by Hatty et al. [11] under similar conditions but still much smaller than for bulk silica in the water at room temperature $25^{\circ} \mathrm{C}$ [1].

The measured crack propagation rates were fitted by the following empirical relationship

$$
\frac{\mathrm{da}}{\mathrm{dt}}=v=C\left(K_{\mathrm{I}}\right)^{n},
$$

with the coefficients $C$ and $n$ varying for different conditions as listed in Table 4. Table 4 first shows that the two test configurations provide similar results in the terms of $K-v$ responses. This is extra cross-validation of the method. Then, the value of $n$ significantly decreases with increasing humidity and/or temperature. There are three different stress-crack corrosion regions generally observed in $v-K$ curves. In region III, the crack growth is independent of environmental conditions. Since the applied $K$ is close to $K_{\mathrm{Ic}}$, the propagation is dominated by static fracture mechanisms. Moreover, the crack growth rate in this region exceeds the velocity of the transport of the environmental species. In region II, contrary to region III, the crack growth rate strongly depends on environmental factors. The diffusion of moisture is here the dominant factor limiting the rate of formation of the $\mathrm{Si}-\mathrm{O} / \mathrm{H}_{2} \mathrm{O}_{2}$ complexes responsible for cracking. Hence, this diffusion-limited region leads to a 'plateau' that is influenced by several factors, such as the loading configuration and humidity level. In region I, the crack growth strongly depends again on the stress intensity factor and it varies almost linearly with temperature and moisture level. This region is the characteristic region of stress corrosion. The $\mathrm{d} a / \mathrm{d} t$ in this region can be appropriately fitted by Eq. (2). There is a stress corrosion threshold $K_{\text {Ith }}$ below which no crack extension is possible anymore. The $K_{\text {Ith }} / K_{\text {Ic }}$ ratio can be used to indicate the susceptibility to stress corrosion cracking. In silica glass, this ratio is around 0.4 and lower for some $\mathrm{Al}$ and $\mathrm{Ti}$ alloys around 0.1 . The $n$ value in the literature is in the range of 5-20 for glasses and metals within region $\mathrm{I}$, which agrees with the values we found in laboratory air and dry $\mathrm{N}_{2}$ environment. For higher humidity levels, the value of $n$ is not very representative since it does not pertain to region I anymore.

Based on this analysis, one can briefly discuss the differences shown in Fig. 7e with the literature data. The difference with the bulk values is not attributed to a size effect but to a difference in material structure as a result of the processing temperature. The crack velocity decreases when the deposition temperature decreases as shown in Fig. S3. The temperature at which the $\mathrm{SiO}_{2}$ was grown here is around $1070{ }^{\circ} \mathrm{C}$, smaller than the temperature of processing of bulk silica, and $930^{\circ} \mathrm{C}$ higher than in the study by Hatty et al. [11].

\section{Conclusions and perspectives}

An enhanced crack-on-a-chip test configuration based on internal tensile stress actuation and a crack arrest principle is used to study the fracture toughness and the environmentally assisted crack growth in thermally grown films of $\mathrm{SiO}_{2}$. This approach has many advantages, such as the freestanding conditions compared to many other methods relying on a film-on-substrate, the absence of a pre-cracking method, and the possibility to run a large number of tests without monopolizing any macroscopic equipment (except for the environment chamber). New design principles have been implemented compared with the first generation of test structures to make the approach more robust and reliable. Owing to these improvements, 257 valid test structures made of cracked $\mathrm{SiO}_{2}$ films have been successfully 
(a)

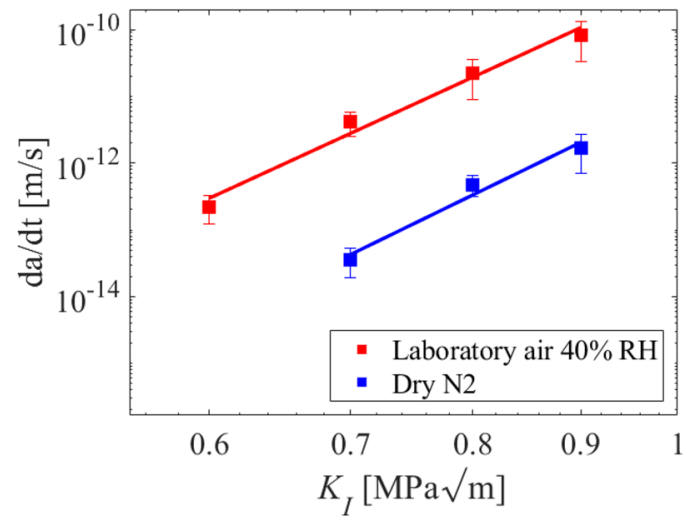

(c)

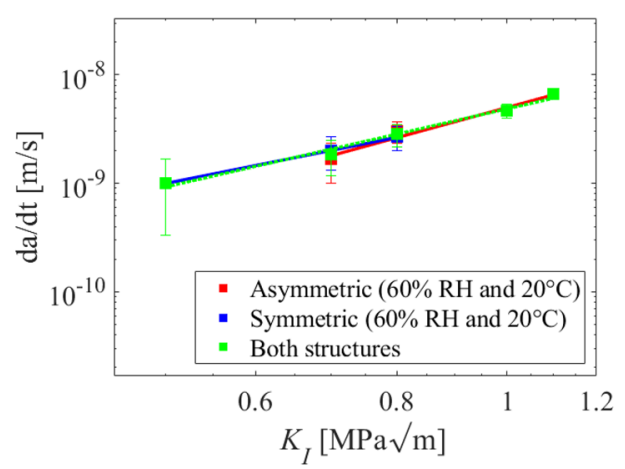

(e)

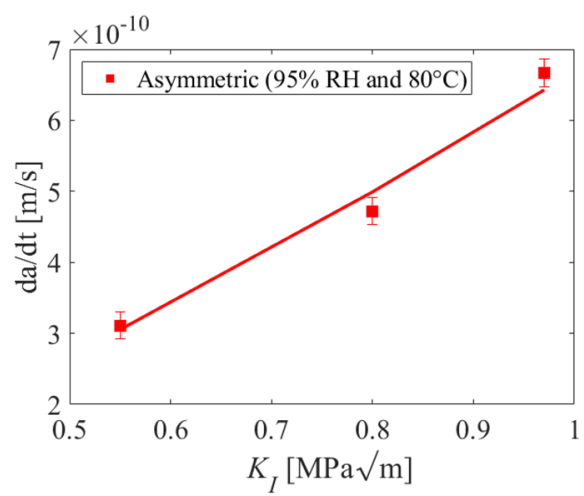

(b)

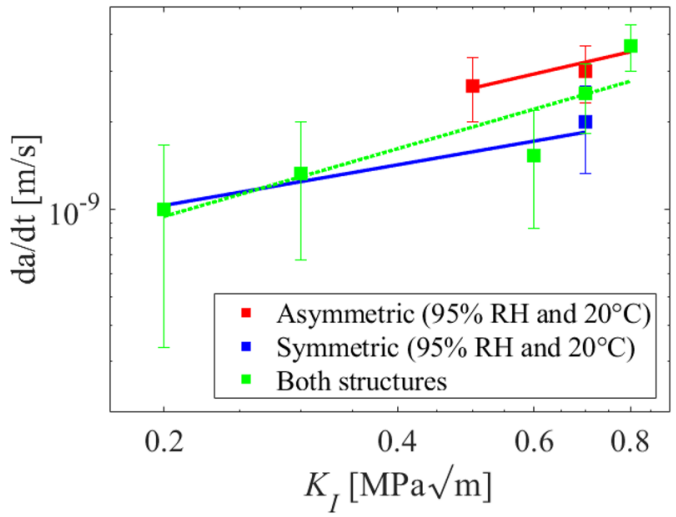

(d)

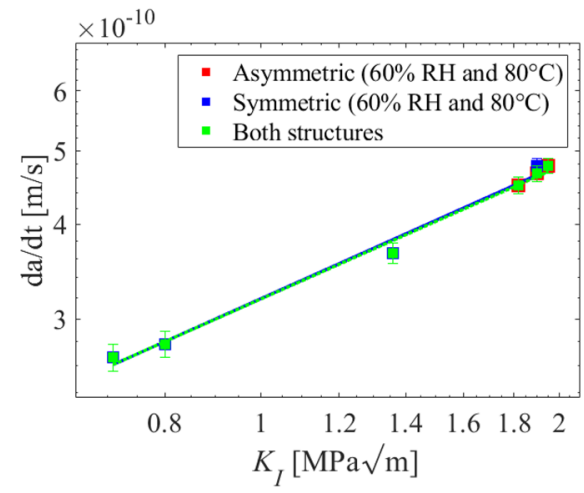

(f)

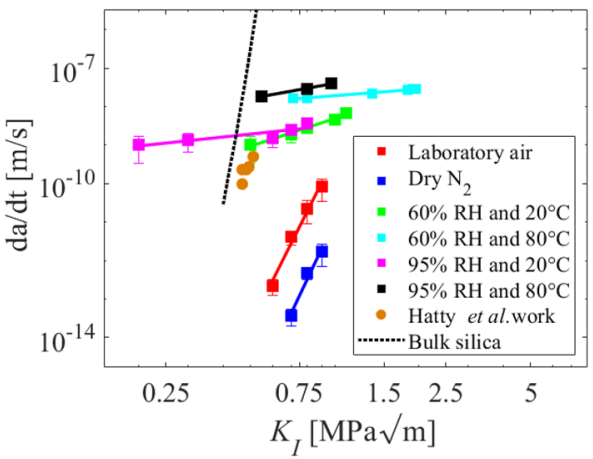

Figure 7: Crack growth rate as a function of driving force $K_{1}$ under different environments: (a) inside a desiccator (shown in blue color) and laboratory air (red color) using asymmetric structures, (b) inside humidity chamber under $95 \% \mathrm{RH}$ and $20^{\circ} \mathrm{C}$, (c) inside humidity chamber under $60 \% \mathrm{RH}$ and $20{ }^{\circ} \mathrm{C}$, (d) inside humidity chamber under $60 \% \mathrm{RH}$ and $80{ }^{\circ} \mathrm{C}$, and (e) inside humidity chamber under $95 \% \mathrm{RH}$ and $80{ }^{\circ} \mathrm{C}$ for asymmetric structures. The graph in green represents the mean value of the crack growth rate by considering the rate given by asymmetric and symmetric configurations. (f) Comparison of crack growth rates in different environments with Hatty et al. (solid circles) [11] at room temperature and inside the water and bulk silica from Widerhorn and Boltz data in water at $25^{\circ} \mathrm{C}$ [1]. 
TABLE 4: Coefficients $n$ and $C$ as a function of the environment conditions for different configurations.

\begin{tabular}{|c|c|c|c|c|c|c|}
\hline & Dry $\mathrm{N}_{2}$ & Ambient air & $60 \% \mathrm{RH}$ and $20^{\circ} \mathrm{C}$ & $60 \% \mathrm{RH}$ and $80^{\circ} \mathrm{C}$ & $95 \% \mathrm{RH}$ and $20^{\circ} \mathrm{C}$ & $95 \% \mathrm{RH}$ and $80^{\circ} \mathrm{C}$ \\
\hline$C\left[\mathrm{~m} /\left(\mathrm{s}(\mathrm{MPa} \sqrt{\mathrm{m}})^{n}\right]\right.$ (asymmetric) & $1.04 \times 10^{-11}$ & $4.95 \times 10^{-10}$ & $5 \times 10^{-9}$ & $1.61 \times 10^{-8}$ & $4 \times 10^{-9}$ & $4.01 \times 10^{-8}$ \\
\hline$n$ (asymmetric) & 15.4 & 14.5 & 2.9 & 0.9 & 0.6 & 1.3 \\
\hline$C\left[\mathrm{~m} /\left(\mathrm{s}(\mathrm{MPa} \sqrt{\mathrm{m}})^{n}\right]\right.$ (symmetric) & - & - & $4.23 \times 10^{-9}$ & $1.92 \times 10^{-8}$ & $2.18 \times 10^{-9}$ & - \\
\hline n (symmetric) & - & - & 2.1 & 0.6 & 0.5 & - \\
\hline$C\left[\mathrm{~m} /\left(\mathrm{s}(\mathrm{MPa} \sqrt{\mathrm{m}})^{n}\right]\right.$ (average) & $1.04 \times 10^{-11}$ & $4.95 \times 10^{-10}$ & $4.86 \times 10^{-9}$ & $1.91 \times 10^{-8}$ & $3.29 \times 10^{-9}$ & $4.01 \times 10^{-8}$ \\
\hline$n$ (average) & 15.4 & 14.5 & 2.4 & 0.6 & 0.5 & 1.3 \\
\hline $\begin{array}{l}\text { Average rate for } \\
\qquad K_{\mathrm{I}}=0.62 \mathrm{MPa} \sqrt{\mathrm{m}}(\mathrm{m} / \mathrm{s})\end{array}$ & $6.6 \times 10^{-15}$ & $4.8 \times 10^{-13}$ & $1.54 \times 10^{-9}$ & $1.43 \times 10^{-8}$ & $2.59 \times 10^{-9}$ & $2.15 \times 10^{-8}$ \\
\hline
\end{tabular}

analyzed. The main findings and contributions of the present work are the following:

- The symmetric cracked configuration experimentally reduces the presence of uncontrolled out-of-plane displacement compared with the asymmetric configuration. This reduces the mode III component.

- The introduction of a spring-type configuration at the clamping extremities reduces the effect of the possible internal stress component parallel to the cracking direction on crack kinking, leading to a majority of test specimens exhibiting valid straight crack propagation path. A dog-bone shape further increases the yield of the method by limiting the stress concentration at the overlap between the test specimen and the actuator beam.

- The new FE simulation-based data reduction scheme takes into account the overetch of the clamping regions, providing excellent predictions of the notch opening and having a first-order effect on the accuracy of the extracted $K$ value.

- The static fracture toughness value of the thermally grown $\mathrm{SiO}_{2}$ films is equal to $K_{\mathrm{Ic}}=0.73 \pm 0.01 \mathrm{MPa} \sqrt{\mathrm{m}}$, consistent with literature data. The standard error of 0.01 is much smaller than the standard deviation of $0.17 \mathrm{MPa} \sqrt{\mathrm{m}}$.

- The $K-\mathrm{d} a / \mathrm{d} t$ curves under different humidity levels and temperatures show crack growth rates two orders of magnitudes smaller in dry $\mathrm{N}_{2}$ compared with laboratory air. By increasing humidity from 60 to $95 \%$, the crack extension rate increases by $\sim 40 \%$, while rising temperature from 20 to $80^{\circ} \mathrm{C}$ leads to 10 times faster cracking. Under high humidity and temperature levels, the crack extension rate belongs to region III contrary to the one measured in dry $\mathrm{N}_{2}$ and ambient laboratory air that belongs to the stress corrosion cracking region I of the $K-v$ curve. The crack growth rates, much smaller than in the bulk, are consistent with the literature when considering the deposition temperature. All these data are generated without monopolizing any external loading devices during load periods of time.
- The symmetric and asymmetric structures provide similar $K-v$ curves, but differ by $\sim 20 \%$ regarding the static toughness for reasons that are not yet fully elucidated as the reduction of the mode III component seems not to be the only dominating factor.

Perspectives involve applications to other systems of interest, for instance under irradiation conditions, as well as the development of a more advanced strategy to take into account the mode III cracking component through modeling the imperfections of the structures.

\section{Methods}

$\mathrm{SiO}_{2}$ films of $142 \mathrm{~nm}$ thick were thermally grown on top of $\mathrm{Si}$ substrate at $1070{ }^{\circ} \mathrm{C}$. The reason for depositing the specimen layer first is the very high temperature which could potentially relax part of the internal stress in the actuating layer if the later would have been deposited first. The internal stress of $\mathrm{SiO}_{2}$ was measured using Stoney's method giving compressive stress of $340 \mathrm{MPa}$. Nanoindentation was used to determine Young's modulus, which is equal to $70 \mathrm{GPa}$. Positive photolithography was employed to pattern the $\mathrm{SiO}_{2}$ specimen followed by plasma reactive ion etching (RIE) technique using a mixture of $\mathrm{CHF}_{3} / \mathrm{O}_{2}$.

Low-pressure chemical vapor deposition (LPCVD) SiN layers were deposited at a high temperature of $790^{\circ} \mathrm{C}$ in a $\mathrm{KOYO}$ vertical furnace VF-100 from Koyo Thermo System Company. The choice of SiN is motivated by its high strength with the beam staying elastic with no viscous relaxation and by its high and reproducible tensile internal stress (note that other actuator choices are also possible and used by our team, such as based on $\mathrm{W}, \mathrm{Al}_{2} \mathrm{O}_{3}$ or $\mathrm{Ni}$ ). A thickness of $98 \mathrm{~nm}$ was measured by ellipsometry. The internal stress of $\mathrm{SiN}$ was measured by wafer curvature relying on Stoney's formula giving 1.1 GPa internal tensile stress. The Young's modulus measured by nanoindentation was equal to $225 \mathrm{GPa}$. The second positive photolithography was carried out to pattern the actuator beams succeeded by RIE etching to remove away non-protective $\mathrm{SiN}$. 
The geometrical parameters such as the length and width of the actuators were measured before release, hence taking into account the lithography inherent errors.

The last step of the process consists of etching the underneath $\mathrm{Si}$ layer in order to release the internal stress stored in $\mathrm{SiN}$. For this purpose, vapor etching using Xenon difluoride $\left(\mathrm{XeF}_{2}\right)$ was selected allowing isotropic etching of $\mathrm{Si}$ while showing excellent selectivity with respect to $\mathrm{SiN}$ and $\mathrm{SiO}_{2}$. About 30 short pulses of $5 \mathrm{~s}$ have been used with pumping the chamber with $\mathrm{N}_{2}$ before and after each pulse to favor the high selectivity between $\mathrm{Si}$ and SiN layers. Thanks to the isotropic etching of $\mathrm{XeF}_{2}$ and the tapered shape of the actuators, the release occurs progressively.

Directly after the release, the sample was taken to a SEM to look at the specimens in which a crack has been initiated and arrested inside the test specimen and to measure the parameters of interest. The SEM is located in the cleanroom facilities where the release is carried out allowing the first measurement of crack arrest lengths after a short transfer period of roughly $5 \mathrm{~min}$. With this short duration, only a limited environmentally assisted crack extension is missed. The crack length was measured as accurately as possible based on the length projected on the long axis of the specimen. The overetching length was also measured. After taking images of different test structures, the die was stored in the desired environment like laboratory air, desiccator, or in a humidity chamber to control the humidity as well as temperature levels.

\section{Acknowledgments}

The authors would like to warmly thank the support of the UCLouvain WINFAB Cleanroom Team, and, in particular, the help of Dr. M. Coulombier. This work was supported by the ARC Project Naturist (Convention No. 11/16-037) and by the FNRS under Grant PDR: T.0178.19. S.J. acknowledges the assistant mandate from UCLouvain.

\section{Open Access}

This article is licensed under a Creative Commons Attribution 4.0 International License, which permits use, sharing, adaptation, distribution and reproduction in any medium or format, as long as you give appropriate credit to the original author(s) and the source, provide a link to the Creative Commons licence, and indicate if changes were made. The images or other third party material in this article are included in the article's Creative Commons licence, unless indicated otherwise in a credit line to the material. If material is not included in the article's Creative Commons licence and your intended use is not permitted by statutory regulation or exceeds the permitted use, you will need to obtain permission directly from the copyright holder.
To view a copy of this licence, visit http://creativecommons.org/ licenses/by/4.0/.

\section{Supplementary Information}

The online version contains supplementary material available at https://doi.org/10.1557/s43578-021-00189-3.

\section{References}

1. S.M. Wiederhorn, L.H. Bolz, Stress corrosion and static fatigue of glass. J. Am. Ceram. Soc. 53(10), 543-548 (1970)

2. S.M. Wiederhorn, Influence of water vapor on crack propagation in soda-lime glass. J. Am. Ceram. Soc. 50(8), 407-414 (1967)

3. S.W. Freiman, Effects of chemical environments on slow crack growth in glasses and ceramics. J. Geophys. Res. Solid Earth 89(B6), 4072-4076 (1984)

4. M. Ciccotti, Stress-corrosion mechanisms in silicate glasses. J. Phys. D 42(21), 214006 (2009)

5. K. Kim, H. Luo, A.K. Singh, T. Zhu, S. Graham, O.N. Pierron, Environmentally assisted cracking in silicon nitride barrier films on poly (ethylene terephthalate) substrates. ACS Appl. Mater. Interfaces 8(40), 27169-27178 (2016)

6. K. Kim, S. Graham, O.N. Pierron, Note: a single specimen channel crack growth technique applied to brittle thin films on polymer substrates. Rev. Sci. Instrum. 88(3), 036102 (2017)

7. K. Kim, H. Luo, T. Zhu, O.N. Pierron, S. Graham, Influence of polymer substrate damage on the time dependent cracking of $\mathrm{SiN}_{\mathrm{x}}$ barrier films. Sci. Rep. 8(1), 1-9 (2018)

8. J.W. Hutchinson, Z. Suo, Mixed mode cracking in layered materials. Adv. Appl. Mech. 29, 63-191 (1991)

9. J.L. Beuth Jr., Cracking of thin bonded films in residual tension. Int. J. Solids Struct. 29(13), 1657-1675 (1992)

10. A.M. Fitzgerald, R.S. Iyer, R.H. Dauskardt, T.W. Kenny, Subcritical crack growth in single-crystal silicon using micromachined specimens. J. Mater. Res. 17(3), 683-692 (2002)

11. V. Hatty, H. Kahn, A.H. Heuer, Fracture toughness, fracture strength, and stress corrosion cracking of silicon dioxide thin films. J. Microelectromech. Syst. 17(4), 943-947 (2008)

12. S. Jaddi, M. Coulombier, J.P. Raskin, T. Pardoen, Crack on a chip test method for thin freestanding films. J. Mech. Phys. Solids 123, 267-291 (2019)

13. A. Boe, A. Safi, M. Coulombier, T. Pardoen, J.P. Raskin, Internal stress relaxation based method for elastic stiffness characterization of very thin films. Thin Solid Films 518(1), 260-264 (2009)

14. M.S. Colla, B. Amin-Ahmadi, H. Idrissi, L. Malet, S. Godet, J.P. Raskin, T. Pardoen, Dislocation-mediated relaxation in nanograined columnar palladium films revealed by on-chip time-resolved HRTEM testing. Nat. Commun. 6(1), 1-8 (2015) 
15. S. Gravier, M. Coulombier, A. Safi, N. André, A. Boé, J.P. Raskin, T. Pardoen, New on-chip nanomechanical testing laboratory-applications to aluminum and polysilicon thin films. J. Microelectromech. Syst. 18(3), 555-569 (2009)

16. P. Lapouge, F. Onimus, R. Vayrette, J.P. Raskin, T. Pardoen, Y. Bréchet, A novel on chip test method to characterize the creep behavior of metallic layers under heavy ion irradiation. J. Nucl. Mater. 476(2016), 20-29 (2016)

17. M. Ghidelli, H. Idrissi, S. Gravier, J.J. Blandin, J.P. Raskin, D. Schryvers, T. Pardoen, Homogeneous flow and size dependent mechanical behavior in highly ductile $\mathrm{Zr}_{65} \mathrm{Ni}_{35}$ metallic glass films. Acta Mater. 131, 246-259 (2017)

18. R. Vayrette, J.P. Raskin, T. Pardoen, On-chip fracture testing of freestanding nanoscale materials. Eng. Fract. Mech. 150, 222-238 (2015)

19. D.H. Alsem, O.N. Pierron, E.A. Stach, C.L. Muhlstein, R.O. Ritchie, Mechanisms for fatigue of micron-scale silicon structural films. Adv. Eng. Mater. 9(1-2), 15-30 (2007)

20. D.H. Alsem, R. Timmerman, B.L. Boyce, E.A. Stach, J.T.M. De Hosson, R.O. Ritchie, Very high-cycle fatigue failure in micronscale polycrystalline silicon films: effects of environment and surface oxide thickness. J. Appl. Phys. 101(1), 013515 (2007)

21. L. Grenet, Mechanical strength of glass. Bull. Soc. Em. Zndrslr. Nut. Paris (5) 4, 838-848 (1899)

22. R.J. Charles, Static fatigue of glass. I. J. Appl. Phys. 29(11), 1549-1553 (1958)

23. S.M. Wiederhorn, Strength of Glass-A Fracture Mechanics Approach. No. NBSIR-74-485 (National Bureau of Standards, Institute for Materials Research, Washington, DC, 1974).

24. T.A. Michalske, S.W. Freiman, A molecular mechanism for stress corrosion in vitreous silica. J. Am. Ceram. Soc. 66(4), 284-288 (1983)
25. T.A. Michalske, S.W. Freiman, A molecular interpretation of stress corrosion in silica. Nature 295(5849), 511-512 (1982)

26. J.P. Lucas, N.R. Moody, S.L. Robinson, J. Hanrock, R.Q. Hwang, Determining fracture toughness of vitreous silica glass. Scr. Metall. Mater. (US) 32(5), 743-748 (1995)

27. Q. Ma, A four-point bending technique for studying subcritical crack growth in thin films and at interfaces. J. Mater. Res. 12(3), 840-845 (1997)

28. M.W. Lane, H.L. Xia, M.S. Thomas, Environmental effects on cracking and delamination of dielectric films. IEEE Trans. Device Mater. Reliab. 4, 142-147 (2004)

29. M.W. Lane, J.M. Snodgrass, R.H. Dauskardt, Environmental effects on interfacial adhesion. Microelectron. Reliab. 41(9-10), 1615-1624 (2001)

30. H. Li, T.Y. Tsui, J.J. Vlassak, Water diffusion and fracture behavior in nanoporous low-k dielectric film stacks. J. Appl. Phys. 106(3), 033503 (2009)

31. Y. Lin, T.Y. Tsui, J.J. Vlassak, Water diffusion and fracture in organosilicate glass film stacks. Acta mater. 55(7), 2455-2464 (2007)

32. Y. Lin, J.J. Vlassak, T.Y. Tsui, A.J. McKerrow, Environmental effects on subcritical delamination of dielectric and metal films from organosilicate glass (OSG) thin films. Mater. Res. Soc. Symp. 766, 171-176 (1999)

33. C.F. Shih, R.J. Asaro, Elastic-plastic analysis of cracks on bimaterial interfaces: part I-small scale yielding. J. Appl. Mech. 55(2), 299-316 (1988)

34. J.R. Taylor, An introduction to error analysis: the study of uncertainties in physical measurements. Meas. Sci. Technol. 9, 022 (1997) 